\title{
DEVELOPMENT AND VALIDATION OF EEVC WG17 LOWER LEGFORM FE MODEL FOR PEDESTRIAN SAFETY
}

\author{
Khoo Y.C ${ }^{1}$, F. Tarlochan ${ }^{2}$ \\ ${ }^{1,2}$ Center for Innovation and Design, College of Engineering, Universiti TenagaNasional, 43009 Selangor
}

\begin{abstract}
Vehicle-pedestrian collisions had claimed the lives of many in the world roads yearly. Among the types of injury that may occur in a vehicle-pedestrian collision, lower extremity injuries have the highest account. These alarming statistic has encouraged joining effort from researchers, car manufacturers and the government to find solutions in reducing the risk of vulnerable road users. The car bumper structure design plays a crucial role in cushioning the impact on the pedestrian leg during a collision. The European Enhanced Vehicle-Safety Committee (EEVC) has developed test methods to evaluate severity of the lower leg injury, upper leg injury and head impact injury in a vehicle-pedestrian simulated collision. Since lower extremity injury are most common, undivided attention should be paid on the lower legform to bumper test. The maximum bending angle, maximum shearing displacement and maximum tibia acceleration are among the three injury criterion determined for lower legform to bumper test. Before the lower legform to bumper test can be perform the lower legform has to be certified statically and dynamically.
\end{abstract}

The advancement of computerization had supported the usage of Finite Element Method(FEM) in simulating real life scenarios for analysis. Irregular geometries are now discretized and solved numerically. Finite Element Analysis(FEA) has proven to reduce time and cost significantly therefore the author took advantaged of this tool and simulated a lower legform to bumper collision. This paper presents in detail the static and dynamic certification of the Finite Element (FE) legform model using the HyperWorks software. The static results for both bending and shearing has to be within the EEVC/WG17 limits and the internal energy at $15^{\circ}$ shall be $100 \pm 7 J$. The maximum bending angle shall not be less than $6.2^{\circ}$ and not more than $8.2^{\circ}$, the maximum shearing displacement shall not be less than $3.5 \mathrm{~mm}$ and not more than $6 \mathrm{~mm}$, and the maximum upper tibia acceleration shall not be less than $120 \mathrm{~g}$ and not more than $250 \mathrm{~g}$ in the dynamic certification test.

Index Terms: Pedestrian Safety, Legform Impactor, EEVC WG17, Finite Element Analysis

\section{INTRODUCTION}

World Health Organization (WHO 2013) reported that more than 270000 pedestrian in the world loses their lives on the roads yearly. This amount contributes to 22 percent of the 1.24 million road traffic deaths around the world.[1] Millions of pedestrians suffer serious injuries in traffic accident and some unfortunate victims become permanently disabled. These tragical injuries and deaths cause immeasurable heartache and inconvenience to both family members and friends especially individuals who are economically challenged. Globalization in low and middle-income countries has led to an increase in motorization, accounting to 52 percent out of 1.6 billion globally registered vehicles[6]. The escalation in vehicle usage contributes to a higher probability in the occurrence of pedestrian-vehicle accident

The common injuries in a pedestrian-vehicle collision includes dislocation of the pelvis, fracture of bones, torn of ligaments and head damage. The International Harmonizes Research Activities' (IHRA) statistic has shown than 67.1 percent of the lower extremities are caused by the car bumper, 12.1 percent by the bonnet leading edge and 7.6 percent by the front panel of the vehicle structure.[2] Due to the high percentage of lower extremity injuries, considerable effort needed to be focused on re-engineering the car bumper system to mitigate pedestrian lower extremity injuries and hence the author will focus on the lower leg. Injuries on the lower extremities include fracture of the bones and a tear in any of the knee ligaments i.e anterior cruciate ligament (ACL), posterior cruciate ligament (PCL), lateral collateral ligament (LCL) and medial collateral ligament (MCL) [7].

The alarming pedestrian fatalities statistic has raised global awareness on pedestrian safety, prompting researchers and car manufacturers to improve the current vehicle design. Many government and independent agencies such as the European New Car Assessment Program (Euro NCAP), Japan New Car Assessment Program (JNCAP), Japan Automobile Manufacturers' Association (JAMA), the Japan Automobile Research Institute (JARI) and National Highway Traffic Safety Administration (NHTSA) in the United States took the initiative to perform crash test and in-depth research on pedestrian protection. 
The basis of this study follows the test procedure proposed by the European Enhanced Vehicle-Safety Committee Working Group 17 Report (EEVC/WG17)EEVC (2002). A legform impactor is a tool used to evaluate the severity of the leg injury in a vehicle-pedestrian simulated collision. The EEVC lower legform impactor consists of a deformable knee joining two $70 \mathrm{~mm}$ diameter rigid steel tubes that represents the tibia and femur. The tubes are covered with $25 \mathrm{~mm}$ CF- 45 Confor Foam representing flesh and $6 \mathrm{~mm}$ Neoprene representing the skin. The knee joint is capable of lateral bending and shearing. The shearing displacement of the knee, bending angle of the knee and the tibia acceleration are measured to evaluate the severity of the injury. The shearing displacement is used to evaluate cruciate ligament injuries, the bending angle is used to evaluate collateral ligament injuries and the tibia acceleration is used to evaluate the tibia fracture risk[8].

The main objective of this study is to use Finite Element Analysis (FEA) to simulate the static and dynamic certification of the lower legform impactor according to the EEVC/WG17 procedures.

\section{EEVC/WG17 LOWER LEGFORM IMPACT}

\section{TEST}

In this study, the author used the EEVC WG17 as a reference to ensure the FE legform model complies with appropriate performance requirements. Although the standard caters for three test methods; legform to bumper test, upper legform to bonnet leading edge test and the headform to bonnet top test, the author will only focus on the legform to bumper test as this is the only test that caters for injuries on the lower extremities. The validation of the lower legform impactor consists of two parts, which are the static test and the dynamic test. The static test is further divided into knee bending test and knee shearing test.

\section{1-STATIC TEST}

\subsection{1- Bending Test}

A bending test set-up shown in Figure 1 is proposed in the EEVC/WG17 whereby the tibia is being fully constrained. A horizontal normal force is applied to the metal tube at a distance of $2.0 \pm 0.01 \mathrm{~m}$ from the center of the knee joint. The corresponding knee bending angle was recorded and the load shall be increased until the knee bending angle is in excess of 22 degree. The energy taken to generate 15 degree of bending shall not be more than $100 \pm 7 \mathrm{~J}$. According to the EEVC/WG17 report, the energy limit function to minimise variation in performance of the deformable elements [3]. The energy can be calculated by integrating the force with respect to the bending angle in radians, and by multiplying the lever length of $2.0 \pm 0.01 \mathrm{~m}$. The corresponding knee bending angle were compiled and the applied force in Newton against the knee bending angle in Degrees was plotted and compared with the EEVC limitations [3].

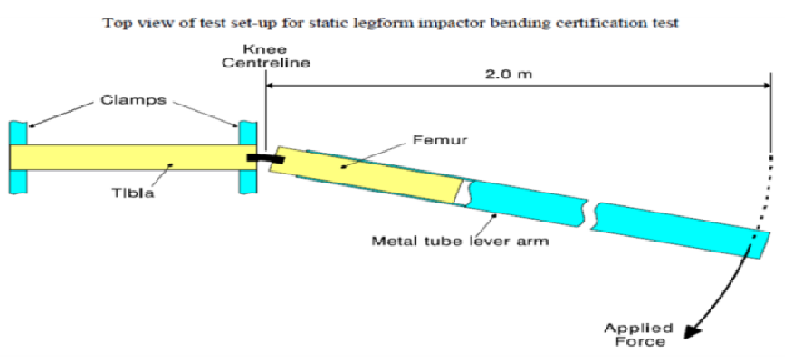

Figure 1: Top view of test set-up for static legform impactor bending certification test [3]

\subsection{2- Shearing Test}

Figure 2 shows the test set-up for shearing of the certification. The tibia was fully constrained while the femur was restraint $2.0 \mathrm{~m}$ from the center of the knee joint. A horizontal normal force was applied on the femur $50 \mathrm{~mm}$ from the center of the knee joint. The load shall be increased until the shearing displacement of the knee reaches an excess of $8.0 \mathrm{~mm}$ or the load is in excess of $6.0 \mathrm{kN}$. The corresponding knee shearing displacement was recorded and plotted against the applied force.[3]

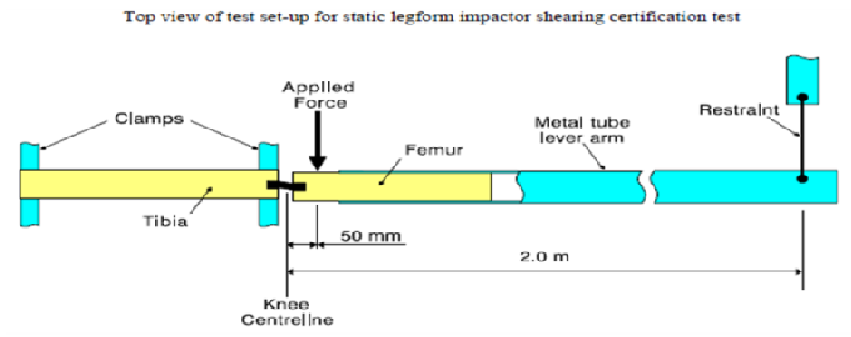

Figure 2: Top view of test set-up for static legform impactor shearing certification test [3]

\section{2- DYNAMIC TEST}

For dynamic test certification, the legform impactor is with foam and skin covering. It shall be suspended horizontally by three wire ropes of $1.5 \pm 0.2 \mathrm{~mm}$ diameter and of $2.0 \mathrm{~m}$ minimum length as shown in figure 3 . The legform impactor shall be suspended along its longitudinal axis horizontally with a tolerance of $\pm 2^{\circ}$. The total mass of the femur and tibia shall be $8.6 \pm 0.1 \mathrm{~kg}$ and $4.8 \pm 0.1 \mathrm{~kg}$ respectively, and the total mass of the legform shall be $13.4 \pm 0.2 \mathrm{~kg}$. The centre of gravity of the femur and tibia shall be $217 \pm 10 \mathrm{~mm}$ and $233 \pm 10 \mathrm{~mm}$ from the center of knee respectively. The moment of inertia of the femur and tibia, about the horizontal axis through respective centre of gravity and perpendicular to the direction of impact, shall be $0.127 \pm 0.010 \mathrm{kgm} 2$ and $0.120 \pm 0.010 \mathrm{kgm} 2$. A uniaxial accelerometer shall be mounted on the non- 
impacted side of the tibia, $66 \pm 5 \mathrm{~mm}$ below the knee joint center. Refer to figure 5, for legform impactor with skin and foam covering.

The certification impactor shall have a mass of $9.0 \pm 0.05 \mathrm{~kg}$, the mass includes those propulsion and guidance components which are effectively part of the impactor during the impact. The dimension of the face of the certification impactor shall be as specified in figure 6 . The impactor shall be made of aluminium alloy with an outer surface finish of better than $2.0 \mu \mathrm{m}$. The certification impactor shall be propelled horizontally at a velocity of $7.5 \pm 0.1 \mathrm{~m} / \mathrm{s}$ into a stationary legform impactor as shown in figure 3 and 4.

When the legform impactor is impacted by a linearly guided certification impactor, the maximum upper tibia acceleration shall be not less than $120 \mathrm{~g}$ and not more than $250 \mathrm{~g}$. The maximum bending angle shall be not less than $6.2^{\circ}$ and not more than $8.2^{\circ}$. The maximum shearing displacement shall be not less than $3.5 \mathrm{~mm}$ and not more than $6.0 \mathrm{~mm} \mathrm{[3].}$

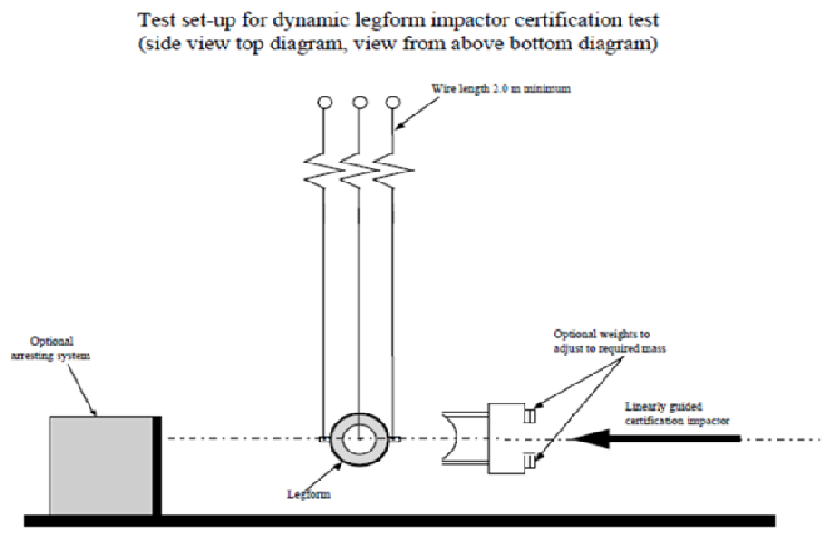

Figure 3: Side view-Test set-up for dynamic legform impactor certification test [3]

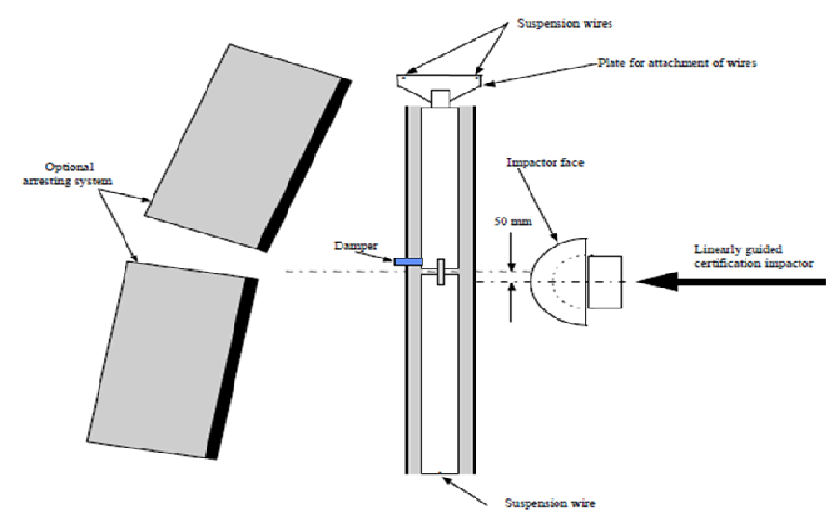

Figure 4: Top view- Test set-up for dynamic legform impactor certification test [3]

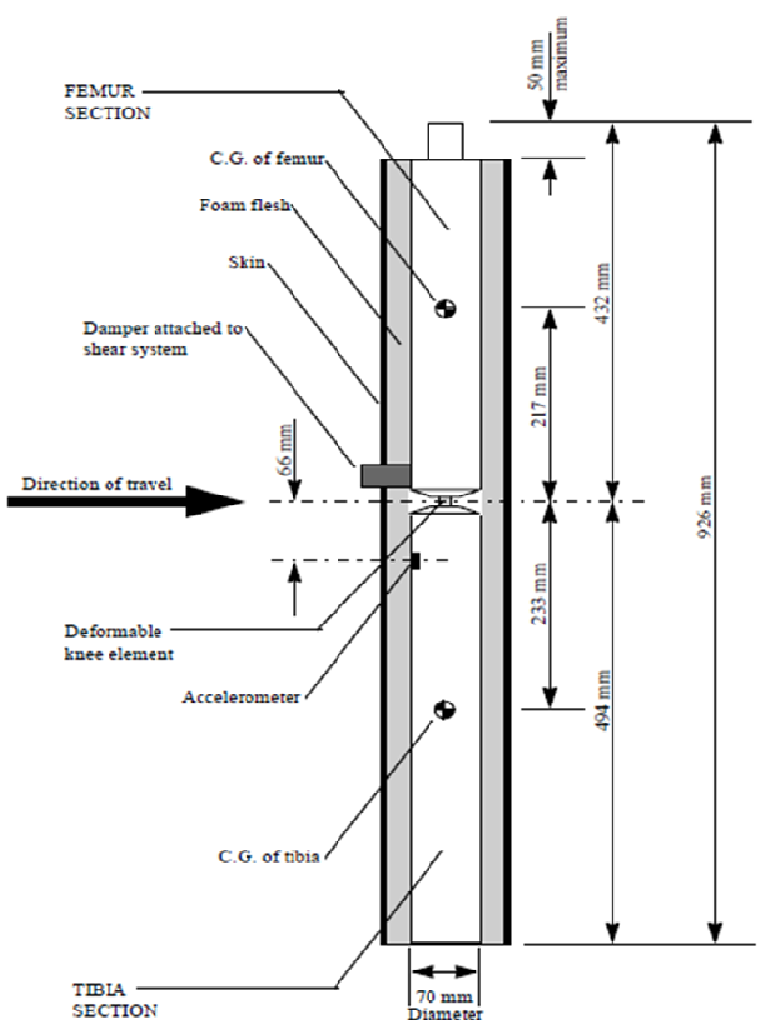

Figure 5: Legform impactor with skin and foam covering [3]

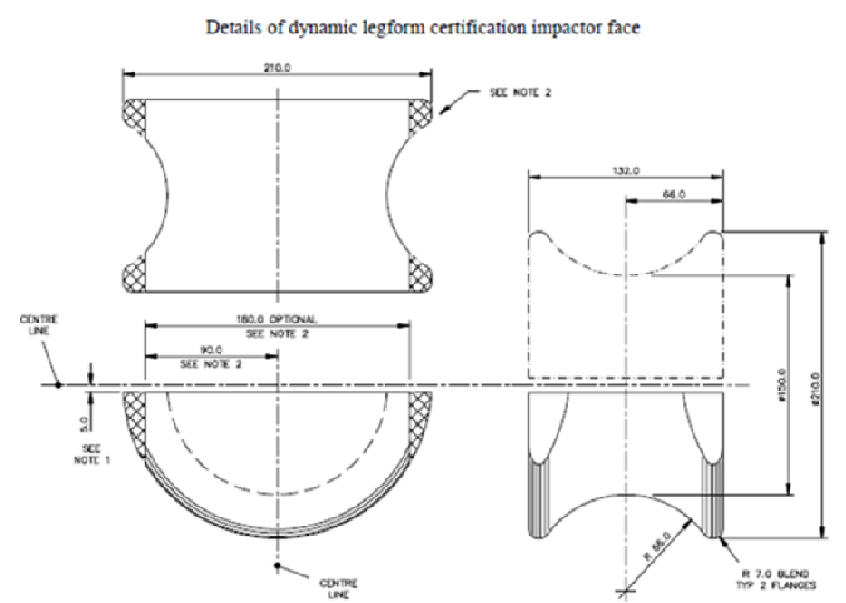

Figure 6: Detail dynamic legform certification impactor [3]

\section{LOWER LEGFORM FINITE ELEMENT} MODEL

\section{1- STATIC TEST}

\subsection{1- Bending Test}

The static bending test was represented in the FE model, Hypercrash interface as shown in figure 7 . The sides of the 
tibia was fully constrained, defining clamps holding the tibia. Shell elements were used to model all parts in the static bending test with steel properties assigned. A $16 \mathrm{~mm}$ diameter cylindrical knee joint was modelled with the length of $20 \mathrm{~mm}$, a thickness of $3 \mathrm{~mm}$, density of $1100 \mathrm{~kg} / \mathrm{m} 3$ and Young's modulus of $650 \mathrm{MPa}$. Concentrated force was applied at $2 \mathrm{~m}$ from the center of the knee joint, the normal horizontal force applied is tabulated in table 1 . Type 7 - multi usage contact interface was assigned on the model, as the nodes were well connected, self-impact was applied.

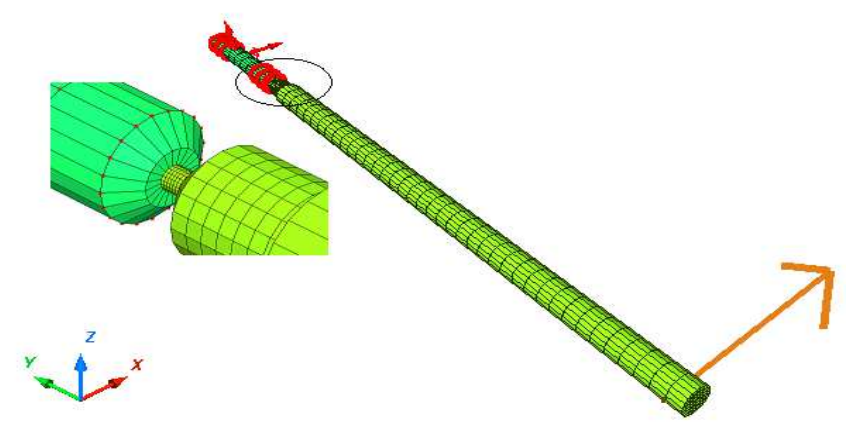

Figure 7: FE model of static bending test set-up

Table 1: Concentrated force(N) applied on static bending test

\begin{tabular}{|l|l|}
\hline $\mathrm{t}$ & $\mathrm{f}(\mathrm{t})$ \\
\hline 1 & 15 \\
\hline 2 & 30 \\
\hline 3 & 55 \\
\hline 4 & 73 \\
\hline 5 & 85 \\
\hline 6 & 97 \\
\hline 7 & 115 \\
\hline 8 & 130 \\
\hline 9 & 143 \\
\hline 10 & 155 \\
\hline 11 & 165 \\
\hline 12 & 175 \\
\hline 13 & 185 \\
\hline 14 & 195 \\
\hline 15 & 200 \\
\hline 16 & 205 \\
\hline 17 & 210 \\
\hline 18 & 215 \\
\hline 19 & 220 \\
\hline
\end{tabular}

\subsection{2- Shearing Test}

The static shearing test is similar to the bending test, therefore the FE model was modified to achieve the static shearing test set up. An additional $2 \mathrm{~mm}$ flat bar was added to restraint the femur movement. In addition, the concentration force was applied 50mm from the center of the knee joint. All material and properties used are the same as the static bending test. Figure 8 and table 2 shows the static shearing test set up and the normal horizontal force applied.

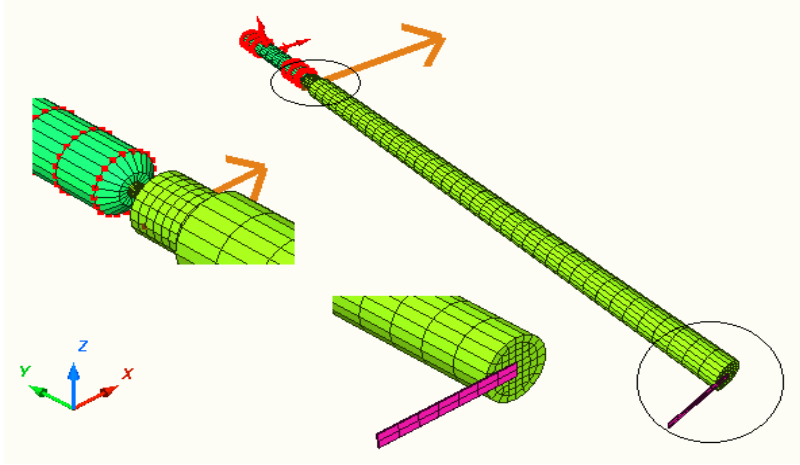

Figure 8: FE model static shearing test set up

Table 2: Concentrated force $(\mathrm{N})$ applied on static shearing test

\begin{tabular}{|l|l|}
\hline$t$ & $f(t)$ \\
\hline 0 & 0 \\
\hline 1 & 300 \\
\hline 2 & 700 \\
\hline 3 & 1400 \\
\hline 4 & 2250 \\
\hline 5 & 2900 \\
\hline 6 & 3500 \\
\hline 7 & 3700 \\
\hline 8 & 3900 \\
\hline 9 & 4100 \\
\hline
\end{tabular}

\section{2- DYNAMIC TEST}

The dynamic certification involves a more complex set up, with an additional covering of $25 \mathrm{~mm}$ flesh and $6 \mathrm{~mm}$ skin. The tibia, femur and knee joints were modeled using shell elements using the exact properties used in the static test, while the flesh and skin were modeled using solid elements. Both femur and tibia were assigned as rigid bodies with the material properties of steel. A mass of $6.87 \mathrm{~kg}$ and $2.65 \mathrm{~kg}$ was added respectively on the femur and tibia rigid bodies, satisfying the weight requirement of $8.6 \mathrm{~kg}$ for femur and $4.8 \mathrm{~kg}$ for tibia, forming a legform impactor of total $13.4 \mathrm{~kg}$. The center of gravity of the femur and tibia was tuned in the software to $711 \mathrm{~mm}$ and $261 \mathrm{~mm}$ from the end of legform. The moment of inertia of femur about the horizontal axis through it's center of gravity and perpendicular to the direction of impact is $0.128 \mathrm{kgm} 2$ while the moment of inertia of tibia is $0.126 \mathrm{kgm} 2$.

As specified in EEVC/WG17, CF45-Confor foam was used in representing the flesh of the human leg. The solid element was interpreted as material type 70 in Hypercrash, foam with 
tabulated law. The density assigned to the material was $96.11 \mathrm{~kg} / \mathrm{m} 3$ with an inital young modulus of $100 \mathrm{MPa}$ and a poison ratio of 0.28 as reference to Alireza Noorpoor and Kiasat (2008)[4] . The stress and strain curved assigned to the foam was tabulated in figure 9, the value was modified based on Shahbeyk and Abvabi (2009) [5].

Neoprene was used to represent the skin in the simulation, the arthur had modeled solid elements with visco-elastic materialtype 34 in Hypercrash. The initial density assigned was $1100 \mathrm{~kg} / \mathrm{m} 3$ with bulk modulus of $102 \mathrm{MPa}$. The short and long time shear modulus was indicated as $8.45 \mathrm{MPa}$ and $3.90 \mathrm{MPa}$ respectively refering to Shahbeyk and Abvabi (2009) [5]. Figure 10 shows the FE model of the legform used in the dynamic certification test. The mesh density increases near the knee joint area to achieve more accurate results. Due to run time constaint, fine meshes throughout the legform was avoided.

Upon completion of the legform modeling, an aluminium impactor of $9.366 \mathrm{~kg}$ was impacted horizontally at a velocity of $7.5 \mathrm{~m} / \mathrm{s}$ into the stationary legform as shown in figure 11 . Two contact interfaces were applied on the dynamic legform, both using type 7 - multi usage. The first contact applied was self impact on the legform and the second with the impactor as the master and the skin as the slave.

An accelerometer was assigned under the data history panel, this enables the author to extract the upper tibia acceleration in Hyperview.

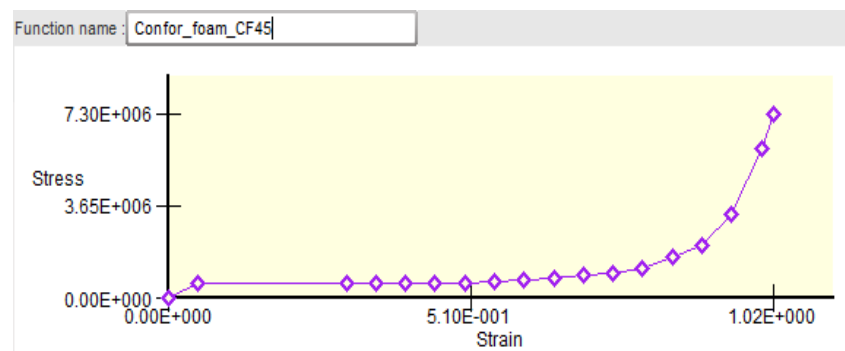

Figure 9: Stress strain curve for Confor foam CF45
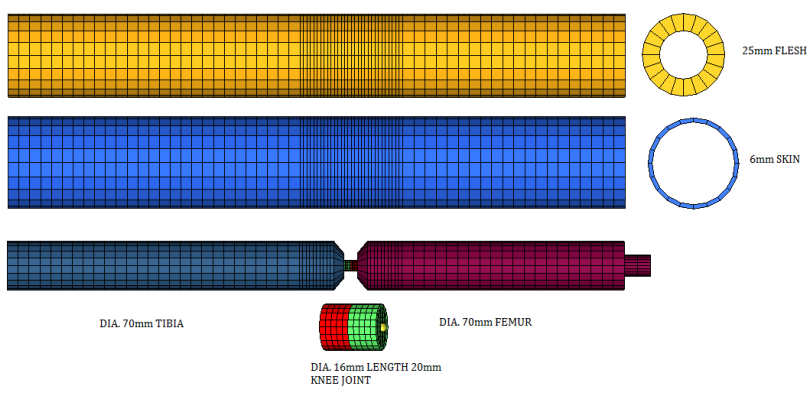

Figure 10: FE dynamic legform model

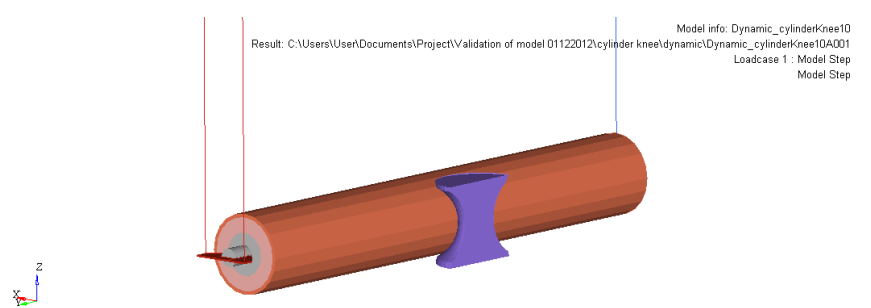

Figure 11: Dynamic certification test set up

\section{VALIDATION OF LOWER LEGFORM IMPACTOR}

\section{1- STATIC CERTIFICATION TEST RESULTS}

\subsection{1- Bending Test}

As specified in the EEVC/WG17 report, the legform has to be certified statically and dynamically. Figure 12 shows the simulation of static bending test set up in the Hypercrash, preprocessor interface. An increasing concentrated force was applied $2 \mathrm{~m}$ from the centre of the knee joint and the resulting bending angle was recorded. A graph of the applied force vs the bending angle was plotted affirming the results were within limits. The energy taken to generate a $15^{\circ}$ bending angle is $106.37 \mathrm{~J}$ which is within the acceptable range of $100 \pm 7 \mathrm{~J}$. Figure 13 shows the bending angle vs force diagram of the simulated results and the EEVC/WG17 limitations.
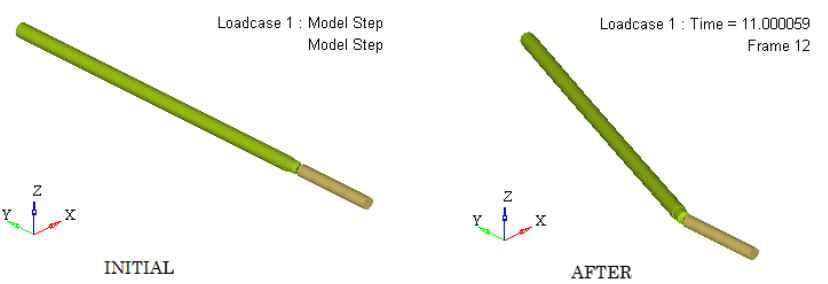

Figure 12: FE Static Bending certification test

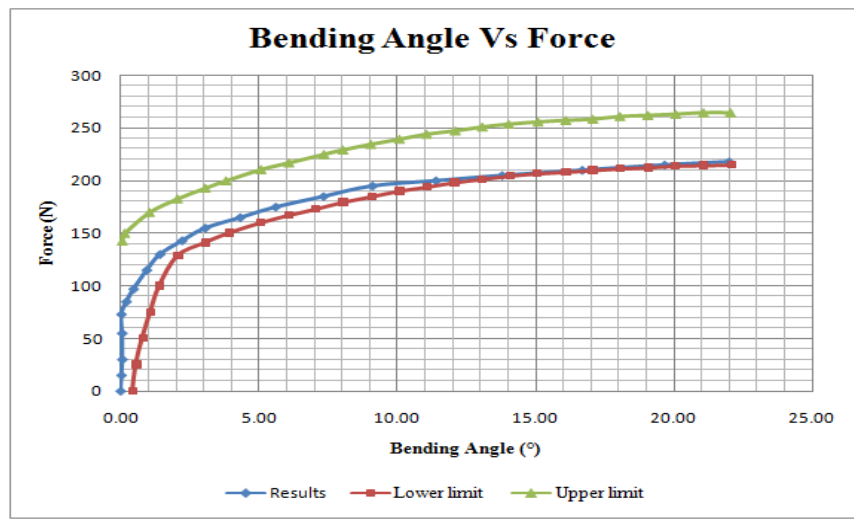

Figure 13: Bending Angle Vs Force graph 


\subsection{2- Shearing Test}

Figure 15 shows the simulation of the static shearing test. For the shearing set-up, the tibia was also fully constrainted at the sides with an increasing force applied $50 \mathrm{~mm}$ from the center of the knee joint. In this test, the shearing displacement was observed. A graph of applied force vs shearing displacement was plotted agaist the EEVC/WG17 limits. The results of the simulation are shown in figure 16 and were proven to be within limitations.

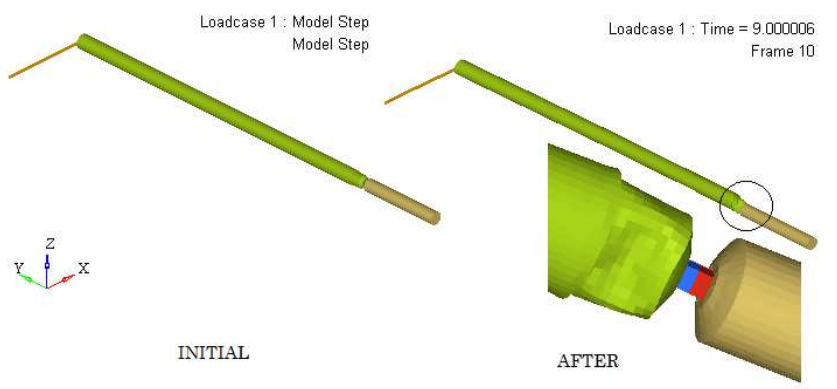

Figure 14: FE Static Shearing certification test

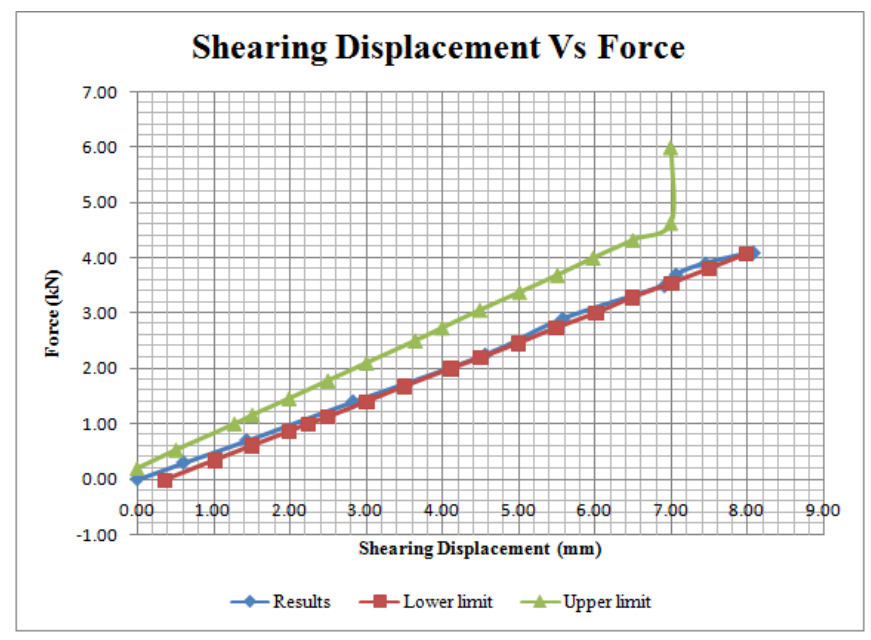

Figure 15: Shearing displacement Vs Force

\section{2- DYNAMIC CERTIFICATION TEST}

\section{RESULTS}

A dynamic simulation was performed with a complete legform with flesh and skin and an aluminium impactor. The impactor has an initial velocity of $7.5 \mathrm{~m} / \mathrm{s}$ and the impacted point is $50 \mathrm{~mm}$ from the center of the knee. The maximum bending angle, maximum shearing displacement and the upper tibia acceleration was observed. Table I shows the results achieved in the dynamic certification and the EEVC limits. It can be observed that the maximum bending angle and the upper tibia acceleration falls within the limitation. Although the shearing displacement did not achieve the minimum shearing displacement of $3.5 \mathrm{~mm}$, it is still within the 20 percent FEA error tolerance.

Table 3: Dynamic certification test result

\begin{tabular}{|l|l|l|}
\hline Criteria & Analysis Results & $\begin{array}{l}\text { EEVC/WG17 } \\
\text { limitations }\end{array}$ \\
\hline $\begin{array}{l}\text { Maximum Bending } \\
\text { Angle }\left({ }^{\circ}\right)\end{array}$ & 8.12 & $6.2-8.2$ \\
\hline $\begin{array}{l}\text { Maximum Shearing } \\
\text { Displacement (mm) }\end{array}$ & 2.83 & $3.5-6.0$ \\
\hline $\begin{array}{l}\text { Upper Tibia } \\
\text { Acceleration (g) }\end{array}$ & 213.86 & $120-250$ \\
\hline
\end{tabular}

\section{CONCLUSIONS}

As lower extremity injuries are most common in vehiclepedestrian collisions, legform testing tool vastly contributes to gauging the injury criterion on the leg during a vehiclepedestrian collision. These testing tools are widely used by car manufacturers in designing pedestrian friendly vehicles. Since the advancement of computerization, finite element analysis has been a popular tool in simulating complex geometry and real life situations due to its accuracy and its cost efficiency. Being said so, finite element analysis and experimental test comes along side, the FE model needs to be validated with experimental results to ensure the modeling and input parameters are accurate.

In this study, a FE legform model was model according EEVC/WG17 specification. In this model, a knee of $16 \mathrm{~mm}$ diameter and $20 \mathrm{~mm}$ of length was modeled as the deformable knee element and the properties was tuned according to the static and dynamic criterion. Upon fulfilling all static and dynamic conditions, the legform is ready to be use for vehicle bumper structure design and optimization.

\section{REFERENCES}

[1] World Health Organization, 2013. Pedestrian safety - A road safety manual for decision-makers and practitioners.

[2] Yoshiyuki Mizuno, 2005. Summary of IHRA Pedestrian Safety WG Activities - Proposed Test Methods to Evaluate Pedestrian Protection Afforded by Passenger Cars.

[3] European Enhanced Vehicle Comittee, 2002. EEVC Working Group 17 Report Improved Test Methods to Evaluate Pedestrian Protection Afforded By Passenger Cars.

[4] Alireza Noorpoor, Akbar Abvabi and Mehdi Saeed Kiasat, 2008. Development a New Model of EEVC/WG17 Lower Legform for Pedestrian Safety. World Academy of Science, Engineering and Technology 41:191-198. 
[5] Sharif Shahbeyk and Akbar Abvabi, 2009. A Numerical Study on the Effect of Accident Configuration on Pedestrian Lower Extremity Injuries. Scientia Iranica.

[6] World Health Organization, 2013. Global Status Report on Road Safety- Section3: Transport policies neglect pedestrians and cylists.

[7] Kei Nagasaka, Koji Mizuno, Eiichi Tanaka, Sota Yamamoto, Masami Iwamoto, Kazuo Miki and Janusz Kajzer. Finite Element Analysis of Knee Injury Risks in Car-to-Pedestrian Impacts. Traffic Injury Prevention, 4:345-354, 2003.

[8] Fuhao Mo, Catherine Masson, Dominique Cesari and Pierre Jean Arnoux. Coupling Lateral Bending and Shearing Mechanisms to Define Knee Injury Criteria for Pedestrian Safety. Traffic Injury Prevention, 14,378-386, 2013.

\section{BIOGRAPHIES}

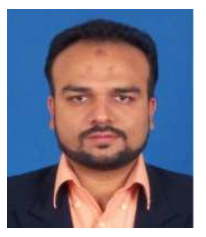

F. Tarlochan was born in Malaysia. He obtained his Bachelors in Mechanical Engineering and Masters in Biomedical Engineering from Purdue University, USA. His PhD was from Universiti Putra Malaysia. $\mathrm{He}$ is currently an Associate Professor at UNITEN and heads the Center for Innovation and Design.

Email: faristarlochan@gmail.com

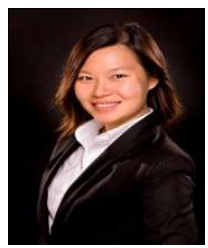

Khoo Y.C was born in Malaysia. She obtained her Bachelors in Mechanical Engineering from Universiti Tenaga Nasiona (UNITEN), Malaysia. She is currently pursuing her masters at UNITEN in the field of Mechanical Engineering. 